\title{
Energy Performance Evaluation for Three Selected Common Commercial Vehicles Based on Fuel Economy
}

\author{
Hayatu Abba Ibrahim, Nura Yakubu \\ Department of Physics, University of Maiduguri, Maiduguri, Nigeria
}

Emails address:

hayatuabbaibrahim5@gmail.com (H. A. Ibrahim)

\section{To cite this article:}

Hayatu Abba Ibrahim, Nura Yakubu. Energy Performance Evaluation for Three Selected Common Commercial Vehicles Based on Fuel Economy. American Journal of Modern Physics. Vol. 7, No. 2, 2018, pp. 62-67. doi: 10.11648/j.ajmp.20180702.11

Received: November 3, 2017; Accepted: November 30, 2017; Published: January 17, 2018

\begin{abstract}
This work is on measurement of automobile performance on Nigerian roads using the method of fuel economy. The current located area is the road linking Maiduguri city to Bama town all in Bono State, Nigeria. The emphasis is made on performance of automobile in relation to fuel consumption with fuel economy. Road safety enhancement is also highlighted. Two particular methods (by two groups of physicists) were first identified for measurement of automobile performance. For reasons of accuracy, one of them was decided for the current study area covering a distance of sixty-six kilometers $(66 \mathrm{~km})$. Three samples of vehicles namely, Golf II, Hiace II and 505 Peugeot Station Wagon were chosen because the 1985 models were found to be commoner. Conditions of the road affected the results. Further, when global averages of the samples were analyzed, except for small deviation, the method verified well. Other useful parameters associated with fuel consumption and fuel economy were also determined. This study particularly finds that the average fuel economy, average energetic performance of both Golf II and 505 Peugeot Station Wagon is equivalent but higher than that of Hiace II.
\end{abstract}

Keywords: Fuel Economy, Energetic Parameters, Vehicles, Roads, Fuel Consumption

\section{Introduction}

The history of the automobile began as early as 1769 . At first, the creation of an internal consumption engine running on fuel gas appeared. This led to the introduction in 1885 of the ubiquitous modern gasoline (or petrol fueled internal combustion engine cars) powered by electric device. The later briefly appeared at the turn of the $20^{\text {th }}$ century, but largely disappeared from use until the turn of the $21^{\text {st }}$ century. The need to reduce the amount of air pollution generated by large number of assorted vehicles has raised new interest in electric and hybrid vehicles. The early history of the automobile can be divided into a number of eras, based on the prevalent method of automotive propulsion during the time. Later periods were defined by trends in exterior styling and size and utility preferences, $[1,2,3]$.

Two groups of scientists $[4,5]$ have carried out studies on measurement of automobile performance. But, the method of would be adopted, in this work. The level of performance of each particular type of automobiles will be measured based on weight groups. The research will provide information to Nigerians, government and non-governmental organizations on the automobile performance with regards to fuel economy.

The study area is located in Borno State, Nigeria. It is the road that links Maiduguri city and Bama town covering a distance of sixty-six (66) kilometers.

It has been realized that the criterion for economy driving, in miles/gallon, has the dimensions of inverse area which leads to the utility of dimensional analysis given by which is given as $\mathrm{m}^{-2}$.

In the western world like United States of America, the fuel economy of cars is usually measured in miles per gallon (mpg). In Nigerian kilometer per liter may be adopted. There is no previous effort available for Nigeria (and by any Nigerian physicist) up to today.

The definitions of fuel economy and fuel consumption as given by are related as

$$
\text { Fuel economy }=(\text { fuel consumption })^{-1}
$$

This means mpg $\equiv(\mathrm{gpm})^{-1}$. Thus, equation (1) above indicates that the fuel economy is inversely proportional to the fuel consumption. That is mile per gallon (fuel economy) is inversely proportional to gallon per mile (fuel consumption). Both fuel economy and fuel consumption are 
techniques among many techniques for measurement of automobile performance.

The fuel consumption of cars is a linear function of the mass of the car. The slope of Hodges straight line is $1.16 \mathrm{x}$ $10^{-10} \mathrm{~m}^{2}$ per unit mass indicating that all 1973 cars reported by Hodges had nearly the same fuel consumption for U. S. A. Also, a report presented by [6] indicates that the fuel economy of cars in U. S. A between 1974 and 1983 has improved by $83 \%$ (during this time period). The result obtained was similar to that of. The slope of the straight line fitted to the 1983 graph is $1.16 \times 10^{-11} \mathrm{~m}^{2}$ per unit mass. This was a significant improvement over the performance reported by Hodges 10 (ten) years earlier. The straight line of graph extrapolates to nearly zero fuel consumption for a car at rest. In this research, the method of Hodges was chosen because of high level of accuracy.

One must consider the vehicle as a system. High fuel economy is considered as one of the attributes that can make vehicles desirable to their owners. Vehicle performance, handling, safety, comfort, reliability, passenger and loadcarrying capacity, size, styling, quietness, and costs are also important features. Governmental regulations require vehicles to meet increasingly stringent requirements, such as reduced exhaust emissions and enhanced safety features. Ultimately these requirements influence final vehicle design, technology content and the fuel economy. Manufacturers must assess trade-offs among these sometimes-conflicting characteristics to produce vehicles that consumers find appealing and affordable.

Engines that burn gasoline or diesel fuel propel almost all passenger cars and light duty trucks. About two-thirds of the available energy in the fuel is rejected as heat in the exhaust and coolant or frictional losses. The remainder is transformed into mechanical energy, or work. Some of the work is used to overcome frictional losses in the transmission and other parts of the drive train and to operate the vehicle accessories (air conditioning, alternator/generator, and so on).

As a result, only about twelve to twenty per cent of the original energy contained in the fuel is actually used to propel the vehicle. This propulsion energy overcomes: (1) inertia (weight) when accelerating or climbing hills (2) the resistance of the air to the vehicle motion and (3) the rolling resistance of the tires on the road. Consequently, therefore two general ways to increase the vehicle fuel economy: (1) increase the overall efficiency of the power train (engine, transmission and drive) in order to deliver more work from the fuel consumed or (2) reduce the required work (weight, aerodynamics, rolling resistance).

Thus, a quantity $\mathrm{Q}$ of central interest is the fuel consumption per unit distance (not per unit time) [7]. Thus the basic equation that relates the coefficient of friction, $\mu$, and other measured parameters like initial velocity, distance, and time can be derived and it is available in most physics texts, [8]. Thus, $\mu$ can be expressed as

$$
\mu=\frac{2(v t-s)}{g t^{2} \cos \theta}-\tan \theta
$$

where, $\mathrm{s}$, denotes the distance, velocity is denoted as $v$, time is $t, g$ is the acceleration due to gravity in $\mathrm{m} / \mathrm{s}^{2}$, and $\theta$ is the angle between the tires and the ground also referred to as angle of inclination. The parameter, $\mu$, therefore, is the coefficient of friction between the tire sand the ground.

That is, there is a resultant force that moves the vehicle forward. So, the work done by the car against air resistance is given by

$$
W=\int_{0}^{t} P d t=\frac{1}{2} \rho v^{3} A C_{D} t=\frac{1}{2} \rho v^{2} A C_{D} x
$$

where $P$ is the power consumed in watts, and $\rho$ is the density of air in $\mathrm{kg} / \mathrm{m}^{3}$. The speed $v$ in equation (3) is assumed to be constant throughout the time interval $t$ in sec. The time $\mathrm{t}$ and the distance travelled $x$ are related by $v=$ $x / t$, where $C_{D}$ is the dimensionless drag coefficient and $A$ is the frontal (or projected) area of the car in $\mathrm{m}^{2}$.

If the drag coefficient, $C_{D}$ and engine efficiency are independent of speed, then the fuel consumption $Q^{\prime}$ is proportional to the work done, $\mathrm{W}$ and the square of the speed. That is, it is expected that the fuel consumption will be of the form

$$
\mathrm{Q}^{\prime}=\mathrm{Q}_{\mathrm{o}}+\mathrm{k} v^{2}
$$

where $Q_{o}$ is the initial consumption of fuel. Q' is the final consumption of fuel and $\mathrm{k}$ is proportionality constant. At higher speeds, the air resistance contribution will also be more. The dimensionless drag coefficient is given as

$$
C_{D}=\frac{2 D}{\rho v^{2} A}
$$

where $D$ is the drag force on the body equivalent to $W / x$ in units of force $(N)$ from equation (3). The power to overcome the air resistance is then given by,

$$
P=\left(\frac{1}{2} \rho v^{3}\right) A C_{D}
$$

Equation (6) implies that, the power requirement of an automobile in overcoming air resistance is a cubic function of speed. It therefore means that power is involved in overcoming air resistance at the higher speed than at the lower speed as given by [9].

It could be noticed that the introduction, so far, has included all necessary rudimentary for the task ahead. The next section is intended to give somewhat detail methodology consisting of the procedures and processes for collecting data. Here, too, tables of values will be presented to include numerically computed physical parameters that are associated with fuel consumption. These are the energetic performance, useful transport work and the fuel transport effectiveness.

The average energetic performance (also called specific resistance) of a vehicle, $\varepsilon$, is obtained from [10] as 


$$
\varepsilon=\frac{P}{W v_{m}}
$$

where $P$ is the output power in Watt, $W$ is the weight of the car in $\mathrm{kg}$, and $v_{m}$ is the mean speed in $\mathrm{m} / \mathrm{s}$. In a subsequent analysis, $[11,12]$, defined the average useful transport work as

$$
\varepsilon_{F}=\frac{\varsigma}{\eta W_{P}}
$$

where $\zeta$ is the energy per unit volume of fuel in Joules $/ \mathrm{m}^{3}, \eta$ is the distance travelled per unit volume of fuel in meters, and $W_{P}$ is the weight of the vehicle pay-load.

The reciprocal of specific fuel expenditure, (another name for $\left.\varepsilon_{F}\right)$ is defined as the fuel transport effectiveness, which is related to car cruising speed $v_{C}$ by

$$
\varepsilon^{-1}=C_{F}^{-1} v_{C}^{-1}
$$

Following [13] definition, the reciprocal of $\varepsilon_{F}$ is defined as the dimensionless ratio of useful work out put to energy input. The factor of proportionality $C_{F}$ can be obtained from equation (9), as

$$
\varepsilon_{\mathrm{F}}=\mathrm{C}_{\mathrm{F}} \mathrm{v}_{\mathrm{C}}
$$

\section{Methodology}

The procedures and processes of collecting data consist of sampling of vehicles and their weight group, followed by determination of the fuel consumption using the Maiduguri Bama road. To sample the vehicles, it was necessary first to seek information from road union workers at the Bama Park, Maiduguri. For analysis purposes, a crucial Inquiry was to know the functions of the region with respect to fuel economy and road Safety procedures. All possible types of vehicles that are used for plying Maiduguri-Bama Road were noted. The Golf II cars, Peugeot station wagon, Peugeot saloon cars and Hiace Buses are common. Three cars were selected out of the four types of passenger cars based on years of manufacture, and other constraints, such as new brand tires, newly fixed carburetor, recently serviced.

Fuel indicator meter already placed on the dash board of the car was checked and noted. The reading of the indicator meter before the start of the journey, and at the point of destination was recorded. This was possible in accordance with the fuel consumption of each car that uses the Maiduguri - Bama road.

Also, the Frontal area of each car was measured using the necessary formula needed on each part of the vehicle depending on the nature of the shape which was be either triangular, rectangular etc. Also, a tape was used to measure the length, breadth, and diameter, etc. The drag coefficient of the a vehicle was determined by using equation (5)

The energy required to move the car a distance of sixty-six kilometers was determined [14]. The density of air which is constant was gotten from a standard table. All data obtained were inserted in appropriate tables. The average velocity of each car was determined. The power to overcome the air resistance of each vehicle was calculated by using the equation (6), which also accords with the energy required to move the vehicle a certain distance $x$ at constant velocity is given by equation (3).

Other parameters include the following: (1) numbers of passengers plus driver for each car were noted; (2) weights of passengers plus the driver for each car were measured; (3) The weights of Passengers' luggage and the driver were measured for each car; (4) tire dimensions, were measured and observed, for load worthiness; (5) The year of manufacture for each car was noted. In addition, the net weight of each vehicle was obtained from the manuals. Total fuel capacity of each car was observed by making used of the manual of each car. It was necessary to know when last each car had service. Fuel mechanism of carburetor type for each was noted. Average speed of the car while travelling between Maiduguri and Bama town was noted by taken into considerations the road worthiness (the good effect and bad effect). The relevant data collected have tabulated in the tables 1 to 4 .

\begin{tabular}{|c|c|c|c|c|c|c|}
\hline Type of cars & Weight (N) & Number of passengers' & $\begin{array}{l}\text { Fuel Capacity } \\
\text { (Liters) }\end{array}$ & Fuel Consumption $\left(\mathbf{m}^{2}\right)$ & Fuel Economy $\left(\mathrm{m}^{-2}\right)$ & Frontal Ares $\left(\mathrm{m}^{2}\right)$ \\
\hline Golf (II) & 16220 & 7 & 60 & 8.103 & 0.124 & 2.6 \\
\hline$"$ & 16160 & $"$ & $"$ & 8.104 & 0.124 & $"$ \\
\hline$"$ & 16190 & $"$ & $"$ & 8.202 & 0.122 & $"$ \\
\hline$"$ & 16280 & $"$ & $"$ & 8.201 & 0.122 & $"$ \\
\hline$"$ & 16150 & $"$ & $"$ & 8.101 & 0.124 & $"$ \\
\hline Hiace (II) & 29820 & 18 & 80 & 9.101 & 0.109 & 3.3 \\
\hline " & 29220 & $"$ & $"$ & 9.04 & 0.111 & $"$ \\
\hline$"$ & 18880 & $"$ & $"$ & 9.01 & 0.111 & $"$ \\
\hline$"$ & 28970 & $"$ & $"$ & 9.02 & 0.111 & $"$ \\
\hline$"$ & 28860 & $"$ & $"$ & 9.30 & 0.108 & $"$ \\
\hline$"$ & 29250 & $"$ & $"$ & 9.10 & 0.109 & $"$ \\
\hline Peugeot 505 & 24580 & 9 & 60 & 9.04 & 0.111 & 4.0 \\
\hline " & 25190 & $"$ & $"$ & 9.05 & 0.111 & $"$ \\
\hline$"$ & 25060 & $"$ & $"$ & 9.80 & 0.102 & $"$ \\
\hline$"$ & 25110 & $"$ & $"$ & 10.01 & 0.099 & $"$ \\
\hline
\end{tabular}

Table 1. Vehicle performance raw data for three types of commercial vehicles manufactured in 1985; the fixed parameters are: (1) Tires are all 14 inches and brand new; (2) Carburetor complied; (3) Recently serviced. Fuel consumption was obtained from the indicator while the fuel economy was obtained using the definition given by equation (1). 


\begin{tabular}{lllllll}
\hline Type of cars & Weight $(\mathbf{N})$ & Number of passengers & $\begin{array}{l}\text { Fuel Capacity } \\
(\text { Liters })\end{array}$ & Fuel Consumption $\left(\mathbf{m}^{2}\right)$ & Fuel Economy $\left(\mathbf{m}^{-2}\right)$ & Frontal Ares $\left(\mathbf{m}^{2}\right)$ \\
\hline$"$ & 24550 & $"$ & $"$ & 10.52 & 0.095 & $"$ \\
$"$ & 25200 & $"$ & $"$ & 10.88 & 0.092 & $"$ \\
$"$ & 25130 & $"$ & $"$ & 11.55 & 0.087 & $"$ \\
\hline
\end{tabular}

Table 2. Tabulation of vehicle performance parameters: The energy to move a vehicle a distance of $66 \mathrm{~km}$ is calculated using equation (1). Here the average speed, $v$, was calculated from two values $100 \mathrm{~m} / \mathrm{s}$ and $90 \mathrm{~m} / \mathrm{s}$ which were obtained from speedometer. The higher speed represents the effect of good road while the lower is due to the effect of bad road. Here and in all subsequent calculations, density of the atmosphere, $\rho$, at standard temperature and pressure, (STP), was obtained from standard table. The drag coefficient, $C_{D}$, was also obtained from [9].

\begin{tabular}{|c|c|c|c|c|c|c|}
\hline Type of cars & Frontal area $\left(\mathrm{m}^{2}\right)$ & $\begin{array}{l}\text { Average } \\
\text { Weight (N) }\end{array}$ & $\begin{array}{l}\text { Energy to move in a } \\
\text { distance of } 66 \mathrm{~km}(\mathrm{~J}) \times 10^{8}\end{array}$ & $\begin{array}{l}\text { Fuel Consumption } \\
\left(\mathrm{m}^{2}\right)\end{array}$ & $\begin{array}{l}\text { Fuel Consumption } \\
(\mathrm{L} / \mathrm{m}) \times 10^{-4}\end{array}$ & $\begin{array}{l}\text { Fuel Economy-my } \\
\left(\mathrm{m}^{-2}\right)\end{array}$ \\
\hline Golf (II) & 2.6 & 16200 & 5.0332 & 8.142 & 1.2333 & 0.123 \\
\hline Hiace (II) & 3.3 & 27500 & 6.3884 & 9.095 & 1.3762 & 0.110 \\
\hline Peugeot 505 & 4.0 & 24974 & 7,7435 & 10.121 & 1.5335 & 0.099 \\
\hline
\end{tabular}

Table 3. Tabulation of average parameters with the corresponding number of test vehicles.

\begin{tabular}{|c|c|c|c|c|c|c|}
\hline \multirow{2}{*}{ Type of vehicles } & \multirow{2}{*}{ Average Weight (N) } & \multirow{2}{*}{ Number test vehicles } & \multicolumn{3}{|c|}{ Fuel Economy $\left(\mathrm{m}^{-2}\right)$} & \multirow{2}{*}{ Average Fuel Consumption $\left(\mathrm{m}^{2}\right)$} \\
\hline & & & Average & Low & High & \\
\hline Golf (II) & 16200 & 5 & 0.125 & 0.122 & 0.124 & 8.140 \\
\hline Hiace (II) & 27500 & 6 & 0.110 & 0.108 & 0.111 & 9.083 \\
\hline Peugeot 505 & 24974 & 7 & 0.099 & 0.087 & 0.111 & 10.121 \\
\hline
\end{tabular}

Table 4. Tabulation of other useful parameters: (i) Power to overcome air resistance was obtained using equation (3); (ii) Average Energetic Performance is by equation (7); (iii) Average Useful Transport Work comes from equation (8); (iv) Average Fuel Transport Effectiveness comes from equation (9).

\begin{tabular}{lllll}
\hline Type of vehicles & $\begin{array}{l}\text { Power to overcome air } \\
\text { resistance }(\mathbf{W}) \times \mathbf{1 0}\end{array}$ & $\begin{array}{l}\text { Average Energetic Performance } \\
(\mathbf{W} / \mathbf{k g} / \mathbf{m} / \mathbf{s})\end{array}$ & $\begin{array}{l}\text { Average Useful Transport } \\
\text { Work } \mathbf{( k g m ) \times 1 0}\end{array}$ & $\begin{array}{l}\text { Average Fuel Transport } \\
\mathbf{E f f e c t i v e n e s s}(\mathbf{m k g} / \mathbf{J})\end{array}$ \\
\hline Golf (II) & 7.245 & 4.692 & 10.726 & 0.213 \\
Hiace (II) & 9.195 & 3.326 & 19.207 & 0.301 \\
Peugeot 505 & 11.146 & 4.685 & 16.528 & 0.213 \\
\hline
\end{tabular}

\section{Results and Analysis}

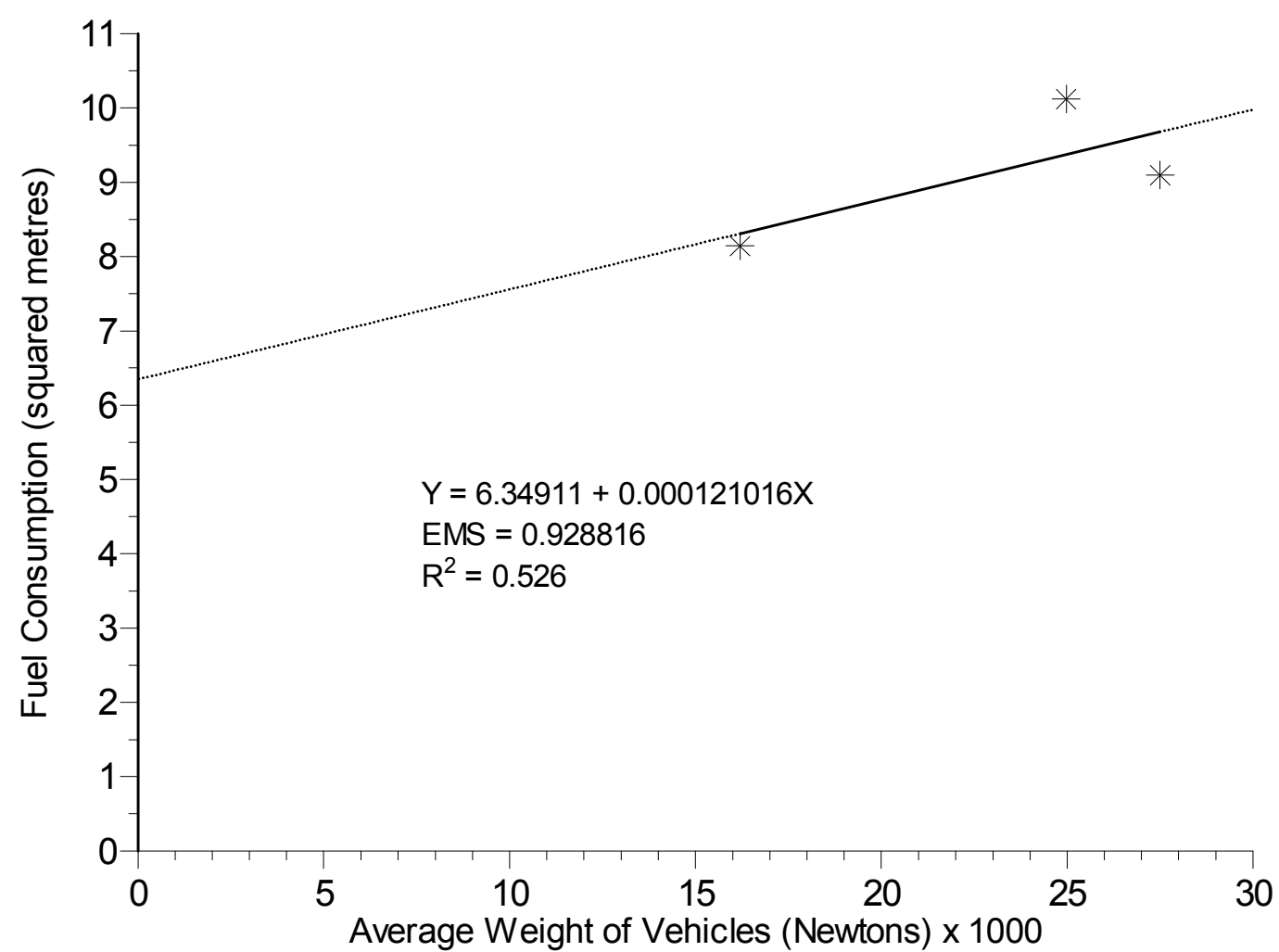

Figure 1. A graph depicting the relation between average weights of three classes of commercial vehicles and fuel consumption in accordance with [4] method. Data obtained from table 3. 
Table 1 contains the records of raw data for the three classes of commercial vehicles chosen. The vehicles were all 1985 models. Tables 2 to 4 obtained are all in accordance with the method. From table 3 a graph was obtained by plotting average fuel consumption against the average weight and a straight line graph (Figure 1) was obtained in agreement with method. But, the straight line did not start from the origin which may be an indication of the discrepancy as a result of bad roads in our country and also due to the ageing effect of the vehicles. An equation of a straight line was obtained and that the error is small which appears to be fairly good. The figure (i.e., Figure. 1) of the straight line graph indicates that the range and mean of average fuel consumption for the particular vehicles is a function of weight (or mass). That means, the straight line plotted was the linear least-squares fit for the average fuel consumption as a function of weight.

\section{Drivers' Guide for Maximumfuel Economy}

The following points are culled excerpts relevant to good driving practice, [15]

(i) Good maintenance culture readily comes to attention. This has to do with proper tire pressure, tire balance and wheel alignment, and engine oil with low kinematic viscosity referred to as low "weight" motor oil. Inflating tires to the maximum recommended air pressure, means that less energy is required to move the vehicle. Under-inflated tires can only increase tires rolling resistance by approximately $14 \%$ for every 0.1 bar drop in pressure of all the four tires of a particular vehicle. Equally, important is the scheduled maintenance of the engine (i.e. air filter, spark plug), and addressing any on-board diagnostic codes/malfunctions in the engine control module and related sensors, especially the oxygen sensor.

(ii) Drivers can also reduce fuel consumption and increase fuel economy by driving lighter and/or lower drag vehicle. Removing common unnecessary accessories such as roof racks, brush guards, wind deflectors, running boards, push bars, and large wire tires improve fuel economy and reduce fuel consumption by reducing both weight and aerodynamic drag. Some cars also use a half size spare tire for weight/cost/space saving purposes.

(iii) Maintaining an efficient speed is an important factor in fuel efficiency. Optimal efficiency can be expected while cruising with no stops, at minimal throttle and with the transmission in the highest gear. The optimum speed varies with the type of vehicle. Drivers of vehicles with fuel economy displays can check their own vehicles by cruising at different speeds and monitoring the readout.

(iv) Road capacity can also affect speed thereby affect efficiency. Studies have shown that speeds just above $72 \mathrm{krn} / \mathrm{h}$ allow greatest fuel efficiency throughout when roads are congested. Individual driver can improve his fuel efficiency and that of others by avoiding congested roads where the traffic flow is up to below $72 \mathrm{krn}$ !h

(v) Engine efficiency varies with speed and torque. For a car engine being engaged in a too low a gear will move the engine into a high-rpm, low torque region in which the efficiency drops off rapidly, and thus best efficiency is achieved at the highest gear. Thus, in a gasoline engine the high efficiency is normally obtained when the car engine is being engaged in a highest gear, as it will move the engine into a smaller rpm and at high torque region.

(vi) Fuel efficiency varies with the type of vehicle. Fuel efficiency during acceleration generally improves as rpm increase until peak torque is achieved. However, accelerating too quickly without paying attention to what is ahead may require braking and then after that, additional acceleration. Experts, recommend accelerating quickly but smoothly.

(vii) The alternative to acceleration and braking is coasting. Coasting is an efficient means of slowing down, because kinetic energy is dissipated as aerodynamic drag and rolling resistance, which must always be overcome by the vehicle during travel. When coasting with the engine running and manual transmission in neutral, or clutch depressed, there will still be some fuel consumption due to the engine needing to maintain idle engine speed. While coasting with the engine running and the transmission in gear, most cars engine control unit with fuel injection will cut off the fuel supply and the engine will continue running, being driven by the wheels.

(viii) A driver may further improve fuel economy and reduce fuel consumption by anticipating the improvement of other traffic users. For example, a driver who stops quickly, or turns without signaling, reduces the options which another driver has for maximizing his performance. By always giving road users as much information about his intentions as possible, a driver can help other road users reduce their fuel usage. Similarly, anticipation of road features such as traffic lights can reduce the need for excessive braking and acceleration.

(ix) $1 \mathrm{t}$ is commonly, believed that efficiency of a gasoline engine is related to the fuel's octane level, however, this is not true in most situations. Octane rating is only a measure of the fuel's propensity to cause an engine to "ping". This ping is due to "precombution", which occurs when the fuel bums too rapidly therefore piston reaches top dead center.

(x) Modern hybrids come with built in trip computers which displays real time fuel economy (mpg) which 
helps the driver to adjust driving habits. High increase of fuel economy is proportional to reduction of fuel consumption [4].

\section{Conclusions}

This work is an attempt to bring into awareness of Nigerians, the need to conserving fuel for safety driving practices, using the techniques of physics. The singular aim has been achieved: this was to determine automobile performance for three classes of commercial vehicles plying the road between Maiduguri city and Bama town. It could be seen that the parameters for automobile performance are the fuel consumption and fuel economy with other associated calculated parameters as tabulated in tables 2 to 4 . Five classes of commercial vehicles were initially desired. The reason is mainly because the analyses as used by required as many as twelve different models of vehicles. But, up to today, there is no effort in the measurement of automobile performance for vehicles in Nigeria in relation to Nigerian roads. Therefore, in addition to the limitation for the distance covered (i.e., sixty-six kilometers of road between Maiduguri and Bama), only the three classes of vehicles could be sampled, owing to limited financial resources at the disposals of the researchers.

In summary, the average energetic performances of both Golf (II) and Peugeot 505 station wagon are equivalent, but that of Hiace is the least. The useful transport work of Peugeot 505 is greater than both that of Hiace and Golf (II). The average transport effectiveness of Golf (II) is greater than both Hiace and Peugeot 505 station wagon. Fuel efficiency of Golf (II) is greater than both Hiace and Peugeot 505 station wagon. Thus, fuel economy and fuel consumption of Peugeot 505 station wagon is the highest, then followed by Hiace and lastly by Golf (II). Golf (II) has the best fuel economy while Peugeot 505 station wagon has the poorest fuel economy. Finally, it is found out that there are three factors which are shape, size and mass of the vehicle as the major contributors to fuel consumption, drag force (air friction), drag coefficient, the average transport effectiveness and the useful transport work.

For a high fuel economy the weight reduction is necessary especially for a passenger cars, so that there will be less fuel consumption and more fuel economy.

\section{References}

[1] Wikipedia, (2011), History of Automobile http://en.wikipedia.org/wiki/History_of_the_automobile.

[2] www.explainthatstuff.com (2016): History of cars: The story of automobile from prehistory today.

[3] Eckermann, Erik (2001). World History of the Automobile SAE Press.

[4] Hodges, L. (1974): Fuel economy of 1973 and 1974 model year automobiles, American Journal of Physics, Vol. 42 (1), $456-458$.

[5] www.nrcan.gc.ca (2017): Fuel consumption guide.

[6] Horton, E. J. and Compton, W. D. (1984): Measurement of auto engine performance, Science, Vol. 225 (4662), 587-593.

[7] Barker, R. E. Jr. (1976): Fuel Consumption due air resistance at high way speeds, American Journal of Physics, Vol. 44 (1), 108-109.

[8] Fowles, G. R. (1977): Analytic Mechanics. U. S. A: HoltSaunders International.

[9] Barlett, A. A. (1988): Physics and the measurement of automobile performance, The Physics Teacher, Vol. 26 (7) 433-435.

[10] Radtke, J. L. (2008): The energetic performance of vehicles, The Open Energy and Fuels Journal, Vol. 1 (3), 11-18.

[11] Teitler, S and Proodian, R. J. (1980): Efficiency of automobiles, Energy, Vol. 4 (2), 46-48.

[12] https://www.ptua.org.au (2015): Cars are becoming more fuel efficient.

[13] Stamper, J. (1975): Energetic performance of automobiles Aeronautical Journal, Vol. 79 (2), 169-178.

[14] Shane brook, J. R. (1974): Power to overcome air resistance at highway speeds, American Journal of Physics, Vol. 42 (11), 1028-1029.

[15] Diken, (2007) Ten fuel saving tips from a hypermiler: MSNBC, http//www.msn.comlid /20706595/). 